\title{
Antihypertensive treatment may have reduced the rate of dementia in older patients with isolated systolic hypertension
}

\author{
Forette F, Seux ML, Staessen JA, et al, for the Syst-Eur Investigators. Prevention of dementia in randomised double-blind \\ placebo-controlled systolic hypertension in Europe (Syst-Eur) trial. Lancet 1998 Oct 24;352:1347-51.
}

\section{Question}

In older patients with isolated systolic hypertension, can antihypertensive treatment prevent dementia?

\section{Design}

Randomised, double blind, placebo controlled trial with up to 5 years of follow up (an optional project in the systolic hypertension in Europe [Syst-Eur] trial).

\section{Setting}

106 centres in Europe.

\section{Patients}

2470 patients who were $\geqslant 60$ years of age and had a systolic blood pressure (BP) (when seated) of 160-219 $\mathrm{mm} \mathrm{Hg}$ and a diastolic BP <95 mm Hg. 2418 patients (98\%) were analysed (mean age $70 \mathrm{y}, 66 \%$ women).

\section{Intervention}

After stratification by sex, centre, and previous cardiovascular complications, patients were allocated to antihypertensive treatment $(n=1238)$ or matching placebo $(n=1180)$. The goal of antihypertensive treatment was to reduce systolic BP by $\geqslant 20$ $\mathrm{mm} \mathrm{Hg}$ or to below $150 \mathrm{~mm} \mathrm{Hg}$. Treatment was started with nitrendipine, $10-40 \mathrm{mg} /$ day. If necessary, nitrendipine was combined or replaced with enalapril, 5-20 mg/day; hydrochlorothiazide, $12.5-25 \mathrm{mg}$ /day; or both drugs.

\section{Main outcome measure}

Incidence of dementia assessed with the DSM-III-R.

\section{Main results}

Analysis was by intention to treat. The Syst-Eur trial was stopped early according to preset stopping rules because antihypertensive treatment led to a greater reduction in stroke than did placebo. After a median follow up of 2 years, 11 new cases of dementia occurred in the antihypertensive treatment group ( 8 Alzheimer's and 3 mixed), and 21 new cases (15 Alzheimer's, 4 mixed, and 2 vascular) occurred in the placebo group $\{\mathrm{p}=0.06\}^{*}$ (table). Time-to-event analysis showed that antihypertensive treatment reduced the dementia rate compared with placebo (3.8 7.7 cases $/ 1000$ person years, $p=0.05$ ).

\section{Conclusion}

In older patients with isolated systolic hypertension, antihypertensive treatment may have led to a reduction in dementia.

*p value calculated from data in article.

Antihypertensive treatment $v$ placebo in older patients with systolic hypertension at a median follow up of 2 yearst

Outcome Antihypertensive Placebo RRR (95\% CI) NNT (CI)

\begin{tabular}{lllll}
\hline Dementia & $0.8 \%$ & $1.8 \%$ & $50.1 \%(-1.5$ to 75.5$)$ & Not significant
\end{tabular}

†Abbreviations defined in glossary; RRR, NNT, and CI calculated from data in article.

Sources of funding: Bayer AG;Belgian National Research Fund; Specia SA;INSERM; drugs supplied by Bayer $A G$ and Merck Sharpe and Dohme.

For correspondence: Professor F Forette, Department of Geriatrics, Hôpital Broca, CHU Cochin, University Paris V.54-56 rue Pascal, 75013 Paris, France. Fax +3344083510.

Abstract and commentary also published in ACP Journal Club.

\section{Commentary}

Systolic hypertension and dementia are common, especially in old people $(\geqslant 85$ years old). The attractive hypothesis that treatment of systolic hypertension reduces the incidence of vascular dementia was a research question of the Syst-Eur trial in $1991 .^{1}$ Forette and colleagues attempted to answer a broader question involving all dementias: Alzheimer's disease, vascular, and mixed forms.

With respect to the original question, only 2 cases of vascular dementia occurred, far fewer than originally predicted. ${ }^{1}$ The claim that systolic hypertension treatment reduced the incidence of all types of dementia by $50 \%$ may constitute a trend, although given that the confidence interval around this estimate included zero, the data are also compatible with no treatment effect. Because these results constitute a post-hoc analy- sis, the possibility of a false positive result arises. The only other comparable study used different drugs and showed no protection against dementia with control of systolic hypertension. ${ }^{2}$

Even if the authors' hypothesis is correct, the safety of calcium channel blockers, especially in the elderly, has been recently questioned. ${ }^{3}$ The generalisability of this efficacy trial is limited because only relatively young patients with few comorbid conditions were included.

What are the clinical implications? Although the exact question initially posed in 1991 was not answered here, the evidence is intriguing and offers hope but, at this stage, nothing more. Good enough reasons (beyond dementia prevention) exist to treat systolic hypertension, at least in people $<85$ years old. With respect to old people with hypertension, especially with comorbid conditions, the jury is still out.

A Mark Clarfield, MD
Sarah Herzog Memorial Hospital
Jerusalem, Israel
Ora Paltiel, MD
Hadassah Medical Centre
Jerusalem, Israel

1 Forette F, Amery A, Staessen J, et al. Is prevention of vascular dementia possible? The Syst-Eur vascular dementia project. Aging (Milano) 1991:3:373-82.

2 SHEP Cooperative Research Group. Prevention of stroke by antihypertensive drug treatment stroke by anthyperth sive drug treatment in older persons with isolated systolic systolic hypertension in the elderly program (SHEP). JAMA 1991;265:3255-64.

3 Opie LH. Calcium channel blockers for hypertension: dissecting the evidence for adverse effects. Am J Hypertens 1997;10:565-77. 